\title{
KONTRIBUSI USAHA TERNAK SAPI TERHADAP PENDAPATAN PETANI DI KECAMATAN KALAWAT KABUPATEN MINAHASA UTARA
}

\author{
Yunior Olii; M. A.V. Manese *); J. Pandey*); I.D.R. Lumenta*) \\ Fakultas Peternakan Universitas Sam Ratulangi Manado, 95115. \\ email: yuniorolii@yahoo.co.id
}

\begin{abstract}
ABSTRAK
KecamatanKalawatmerupakansalahsatuke camatan yang terletak diwilayahKabupatenMinahasa Utara denganluaswilayahsebesar 4.714 ha. UmumnyamasyarakatKecamatanKalawat berprofesisebagaipetani.Populasiternaksap i di KecamatanKalawatadalahsebesar 489 ekor yang tersebar di 12 desa.Masalahdalampenelitianiniadalahber apabesarusahaternaksapidapatmemberika nkontribusiterhadappendapatanpetanipeter nak di

KecamatanKalawatKabupatenMinahasa Utara.Tujuanpenelitianiniuntukmegetahui berapabesarkontribusiusahaternaksapiterh adappendapatanpetani di KecamatanKalawatKabupatenMinahasa Utara.Penelitianinidilaksanakan di KecamatanKalawatKabupatenMinahasa Utara denganjumlahrespondensebanyak 30 orang.Waktupenelitiandanpengumpulan data selama 2 bulan.Data penelitiandiperolehdari 2 sumberyaitu data primer dan data sekunder.Metodepenentuansampeldilakuk ansecaraPurposive

Samplingdenganpenentuanrespondendilak ukansecaraRandom Sampling. Hasilpenelitianmenunjukkanbahwaternaks apimemberikankeuntunganterhadappenda patanpetanisebesar Rp.181.078.967. Adapun total pendapatanusahatanimaupundiluarusahata niadalahsebesar Rp.1.017.128.467. Berdasarkanfaktainimakakontribusiusahat
\end{abstract}

*Dosen Pembimbing ernaksapiterhadappendapatanpetaniadalah sebesar $17,78 \%$.

\section{Kata Kunci:Kontibusi,Ternak Sapi, Pendapatan Petani}

\section{ABSTRACT}

CONTRIBUTION OF BEEF CATTLE BUSSINES TO FARMERS INCOME IN KALAWAT ON NORTH MINAHASA. Kalawatis one of thedistrictsarelocatedinNorth Minahasawitha total area of 4,714ha. Kalawat's people living asfarmers. Population of Beef cattle in the kalawat amounted to489 cattle spread across 12 villages. The problem inthis studyishow much beef cattle businesscan contribute to farmers income in Kalawat, NorthMinahasa. The purposeof this researchistodeterminehow much the beef cattle business give a contributionto theincome of farmersin the Kalawat,NorthMinahasa. The research was conductedin the Kalawatof NorthMinahasawithmanyrespondentsas many as 30people.Duration of the research and data collection is for 2 months. The data in this study were obtained from two sources, primary data and secondary data. Sampling method of purposive sampling is done by determining the respondents were Random Sampling. The results in this study indicate that cattle provide benefits to farmers income by Rp.181.078.967. Total income of farm and out of farm amounted Rp.1.017.128.467. Based on this fact, contribution from cattle bussines to farmers income amounted $17,78 \%$. 


\section{Keywords:Contribution of cattle bussines, farmers income}

\section{PENDAHULUAN}

Ternak sapi merupakan salah satu ternak yang produksi utamanya adalah daging, susu, dan kulit. Usaha peternakan sapi akhir-akhir ini telah memperlihatkan perkembangan yang pesat dan memberikan sumbangan ekonomi yang sangat besar (Susilorini., dkk 2011). Selain sebagai penghasil daging, ternak sapi di Indonesia juga digunakan sebagai sumber tenaga kerja, bahan pupuk organik, biogas, dan tabungan dimasa yang akan datang (Sihombing, 2000).

Usaha peternakan sapi di Sulawesi Utara umumnya masih merupakan usaha peternakan rakyat. Ternak sapi dipelihara untuk memenuhi kebutuhan yang tidak terduga sehingga pada saat-saat tertentu, ketika petani memerlukan uang untuk memenuhi kebutuhan yang mendesak maka ternak sapi tersebut dapat diuangkan/dijual (Tarandung, 2004).

Kecamatan Kalawat merupakan salah satu kecamatan yang terdapat diwilayah Kabupaten Minahasa Utara, dengan luas wilayah 4.714 ha yang terdiri atas 12 desa. Umumnya masyarakat di Kecamatan Kalawat berprofesi sebagai petani. Salah satu jenis ternak yang banyak dipelihara oleh masyarakat petani Kecamatan Kalawat ialah ternak sapi. Berdasarkan data hasil survei yang diambil dari Balai Penyuluhan Pertanian Perikanan dan Kehutahan (BP3K) Kecamatan Kalawat tahun 2011, menyatakan bahwa populasi ternak sapi berjumlah 489 ekor yang tersebar di 12 desa populasi ternak sapi terbesar terdapat pada Desa Kolongan Tetempangan, Desa Watutunou, dan Desa Kawangkoan.

Pemanfaatan ternak sapi di Kecamatan Kalawat saat ini hanya sebatas sebagai tenaga angkutan yang digunakan untuk mengangkut hasilhasil pertanian. Sedangkan pemanfaatan tenaga kerja ternak sapi sebagai tenaga pembajak lahan pertanian tidak dilakukan lagi, sehingga membuat peran ternak sapi sebagai sumber tambahan pendapatan petani semakin berkurang. Dari uraian tersebut maka perlu dilakukan penelitian mengenai berapa besar kontribusi pemeliharaan ternak sapi terhadap pendapatan petani di Kecamatan Kalawat.

Tujuan penelitian ini adalah : Untuk megetahui berapa besar kontribusi usaha ternaksapi terhadap pendapatan usaha petani di Kecamatan Kalawat Kabupaten Minahasa Utara.

\section{MATERI DAN METODE PENELITIAN}

Penelitian ini dilaksanakan di Kecamatan Kalawat Kabupaten Minahasa Utara. Waktu dan pengumpulan data dilakukan selama 2 bulan sejak dari bulan Februari sampai maret 2013.

Penelitian ini dilakukan dengan metode survei. Penelitian survei merupakan suatu teknikpengumpulaninformasi yang dilakukan dengan cara menyusun daftarpertanyaan yang diajukan pada responden. Dalam metodesurvei, penelitian dilakukan dengan meneliti karakteristikvariabel tanpa adanya 
intervensi peneliti (Cochran 2005). Data dalam penelitian ini diperoleh dari dua sumber yaitu data primer dan data sekunder.

Metodepenentuandesasampeldit entukansecaraPurposive

Sampling.PenggunaanteknikPurposive Samplingmempunyaisatutujuanataudil akukandengansengaja

(SuyatnadanAntara,2004).Penentuand esasampelpenelitiandidasarkanataspert imbangandesa-

desatersebutmemilikijumlahpopulasite rnaksapiterbesarsertaterdapatusahapert anian. Adapundesa-desa yang sesuaikriteriatersebutadalahDesaKolon ganTetempangan, DesaWatutumou, danDesaKawangkoan.Berdasarkandes aterpilih,

ditentukanjumlahpetanipeternaksapibe rdasarkankriteriasebagaiberikut :

1. Memilikiternaksapidewasa $\geq 2$ ekor

2. Memilikipengalamanberternak $\geq 3$ tahun

3. Pernahmenjualternaksapi tahunterakhir

\section{HASIL DAN PEMBAHASAN}

\section{KeadaanUmum \\ KecamatanKalawat}

Wilayah

\section{KeadaanUmum Wilayah}

KecamatanKalawatadalahsalah satukecamatan yang yangterletak di wilayahKabupatenMinahasa Utara.LuaswilayahkecamatanKalawat adalah4.714 ha yang terdiridari 12 desa.

JumlahpendudukKecamatanKalawatad alahsebesar 28.251 jiwa.
4. Memilikiusahapertanian/perkebun an

Berdasarkan kriteria diatas, responden ditentukan secara Simple Random Sampling. Untuk penelitian deskriptif, sampel diambil secara random sebesar $10 \%$ dari jumlah populasi untuk mewakili keseluruhan populasi (Mustafa, 2000).

Untuk menjawab tujuan penelitian digunakan analisis deskriptif dimana analisis deskriptif yaitu suatu bentuk penelitian yang ditujukan untuk mendeskripsikan fenomena-fenomena yang ada, baik fenomena alamiah maupun fenomena buatan manusia (Jogianto, 2008). Untuk menghitung besarnya kontribusi usaha ternak digunakan rumus sebagai berikut :

Dimana

$$
A=\frac{B}{B+C+D}
$$

A $=$ Total Kontribusi

B = Kontribusi Usaha Ternak Sapi

$\mathrm{C}=$ Kontribusi Usaha Tani

$\mathrm{D}=$ Kontribusi Luar usaha tani

\section{Karakteristik Responden}

\section{Umur}

Keberhasilan suatu usaha sangat tergantung dari kemampuan seseorang untuk melakukan semua kegiatan untuk memenuhi kebutuhannya. Berdasarkan hasil penelitian, diperoleh keadaan umur responden petani peternak yang bervariasi diantara umur 22 tahun sampai dengan umur 63 tahun. Keadaan umur responden di Kecamatan Kalawat Kabupaten Minahasa Utara dapat dilihat pada Tabel 1. 
Tabel 1. Keadaaan Umur Responden di Kecamatan Kalawat Minahasa Utara.

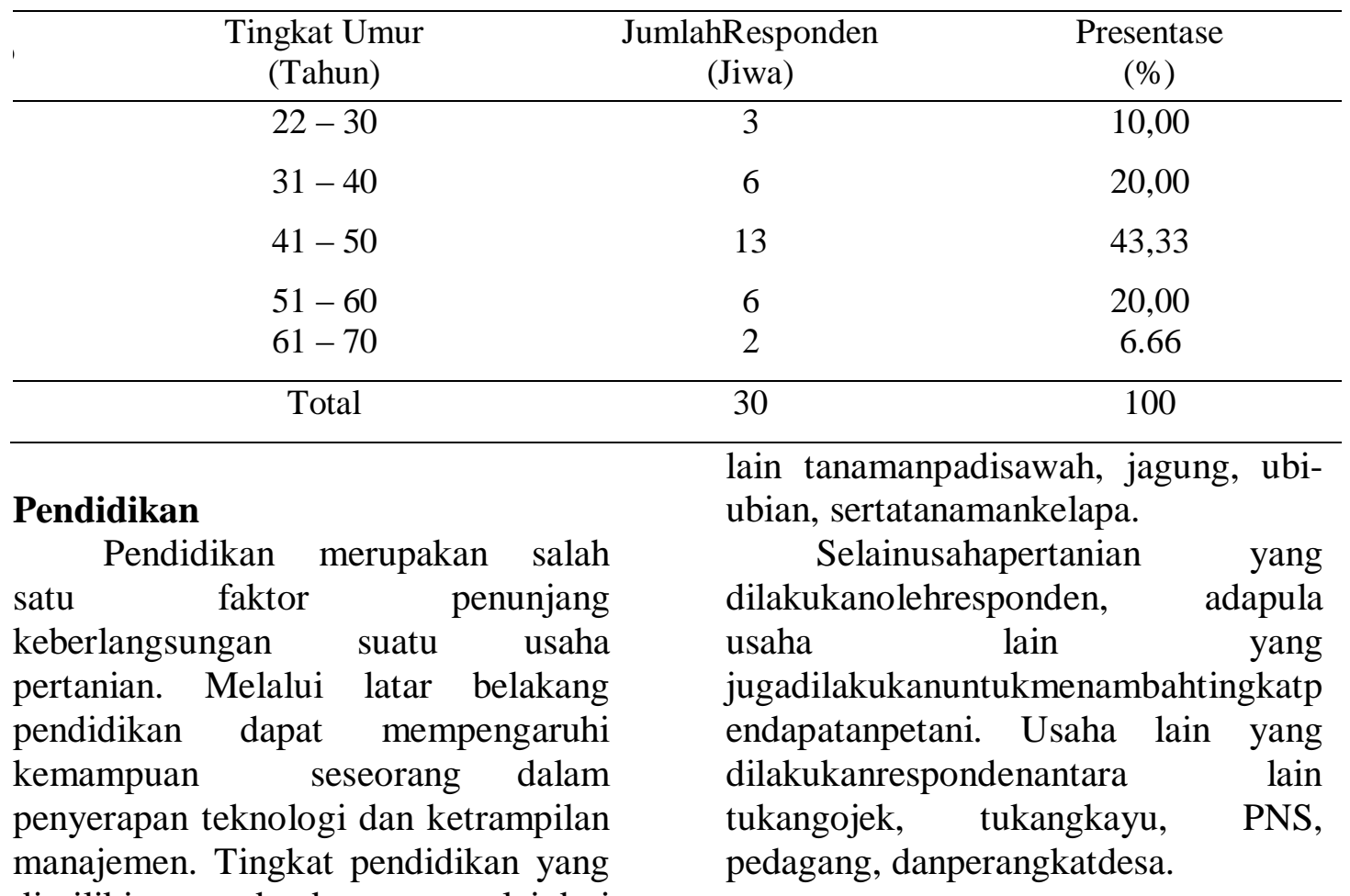

dimiliki responden beragam mulai dari tingkat SD, SMP, SMA, serta Perguruan Tinggi. Adapun tingkat pendidikan terbesar responden ada pada tingkat SD sebesar $56,66 \%$ sedangkan tingkat pendidikan terkecil pada tingkat Perguruan Tinggi sebesar $6,66 \%$

\section{Pekerjaan}

Usaha pertanian di KecamatanKalawatmerupakanmatape ncaharian yang paling banyakdigelutiolehmasyarakatKecama tanKalawat.Hal iniberpengaruh pula terhadapjenispekerjaanresponden.Seba gianbesarpekerjaanrespondenadalahse bagaipetani.Hasilpenelitianmenunjukk anbahwasemuarespondenmemilikiusa hapertanian.

Adapunjenistanamanpertanian yang sedangdiusahakanolehrespondenantara

\section{Status Pemilikan Ternak}

Ternak sapi yang dimiliki merupakan ternak milik sendiri yang diperoleh dengan cara membeli atau bahkan ternak turunan. Jenis ternak sapi yang dipelihara oleh masyarakat Kecamatan Kalawat adalah jenis sapi ongole. Pemilihan jenis sapi ongole didasarkan oleh tampilan fisik sapi yang besar sehingga cocok digunakan sebagai tenaga kerja. Selain itu, bangsa sapi ini tahan terhadap panas dan kwalitas pakan yang jelek (Susilorini., dkk, 2011).

\section{Karakteristik Usaha Pemeliharaan Ternak Sapi}

Biaya Makanan 
Pakanmerupakanfaktor yang menentukankeberhasilandarisuatuusah aternakdisampingfaktorlingkungandan faktormanajemenpemeliharaannya.Sist empemelihara-an ekstensifadalahpemeliharaanternak yang digembalakanselamadipelihara (MulyonodanSarwono, 2004).

Pakan yang lazim diberikan pada ternak sapi adalah rumput alam, limbah dari tanaman jagung, dan batang jagung. Berdasarkan hasil survey penelitian pada responden diketahui bahwa para peternak tidak mengeluarkan biaya pakan dalam mengurus ternak sapi mereka. Hal ini disebabkan para peternak melakukan pemeliharaan ternak sapi secara ekstensif dengan mengembalakan ternak sapi yaitu dengan mengikatkan ternak sapi dikebun, pinggir jalan, dan pematang sawah yang memiliki sumber hijauan yang dapat dimanfaatkan secara gratis sehingga para peternak tidak perlu mengeluarkan biaya pakan dalam memelihara ternak sapi. Dari hasil penelitian diketahui jenis hijauan yang diberikan pada ternak adalah rumput liar dengan jenis rumput Brachiaria humidicola,Stenotaphrum secundatum, Imperata cylindrical.

PenggunaanAlokasiWaktuTenagaK erja

i Skalausahapemeliharaanternaksap masihbersifatsebagaiusahasampingan membuatpemeliharaanternaksapihanya dilakukandenganolehpemilik.Curahan waktukerjarespondendapatdilihatpada Tabel 2.

Rata-rata biayatenagakerja per harirespondenadalahsebesarRp.

18.955,93. Biayatenagakerjaresponden per bulansebesarRp. 17.060.340, ratarata biayaresponden per bulansebesarRp. $\quad 568.678$. sedangkanbiayatenagakerja per tahunsebesarRp. 204.724.080 dengan rata-rata biaya per tahunsebesarRp. 6.824.136.Upahtenagakerjadidaerahpe nelitianadalahsebesarRp. 75.000 per haridengan jam kerjasebesar 8 jam per hari, sehingga total penggunaanwaktutenagakerjauntukme meliharaternaksapidibagidenganjumla h jam kerja.

Tabel 2. Curahan Waktu Tenaga Kerja Responden

\begin{tabular}{clc}
\hline No. & \multicolumn{1}{c}{ Jenis Kegiatan } & Menit/Hari \\
\hline 1 & Mengiring ternak ke padang pengembalaan & 29,16 \\
2 & Memberi Minum Ternak & 19 \\
3 & Memindahkan Ternak & 16,6 \\
4 & Memandikan Ternak & 29,23 \\
5 & Menggiring Ternak Ke Rumah & 29,16 \\
\hline \multicolumn{2}{c}{ Total } \\
\hline
\end{tabular}

Biaya Pengobatan dan Pencegahan Penyakit

Upaya yang dilakukanrespondenterhadappenanggu langankesehatanternakmerekadilakuka ndenganmenanganisendiriternakdanju gamenggunakantenagamantrihewanun tukurusanvaksinasiternak.Obat-obatan yang seringdiberikanolehpeternakdiantarany aminyaktanah, yodium, salep, vitamin 
serta anti biotik.Biayaobat-obatan yang dikeluarkanperbulan rata-rata berkisarRp 12.000-30.000/bulan. Vaksinasiternakdilakukandenganmelih atkondisiternakitusendiri,sehinggakegi atanvaksinasibiasanyahanyadilakukan 1-3 kali dalam 1 tahun. Biaya yang biasadikeluarkanolehpeternakuntukva ksinasisebesarRp. 150.000 .

\section{Penerimaan dan Pendapatan Usaha Beternak Sapi Sebagai Tenaga Kerja}

Rahim dan Diah (2008) menyatakan bahwa penerimaan usaha tani ternak adalah penerimaan dari seluruh sumber usaha tani ternak yang meliputi nilai penjualan hasil, penjualan inventaris, dan nilai produksi yang dikonsumsi petani dan keluarganya selama melakukan kegiatan.

Usaha penyewaan tenaga kerja ternak sapi di Kecamatan Kalawat Kabupaten Minahasa Utara hanya sebatas tenaga kerja d ibidang pengangkutan. Petani di Kecamatan Kalawat lebih cenderung memanfaatkan tenaga kerja ternak sapi untuk mengangkut hasil pertanian kelapa (buah kelapa). Tarif penyewaan yang dikenakan petani sebesar Rp. 200 - Rp 250 per buah kelapa, dengan kapasitas angkutan (gerobak) rata-rata 300 - 450 buah/gerobak. Dimana dalam satu kali panen/satu periode produksi, angkutan disewakan sebanyak $3-7$ kali per periode produksi kelapa.

Berdasarkan hasil perhitungan diketahui bahwa jumlah pendapatan penyewaan ternak per produksi kelapa sebesar Rp. 9.943.750 dengan rata-rata pendapatan peternak sebesar Rp. $523.355,26$. Jumlah pendapatan per tahun sebesar Rp. 29.830.250 dengan rata-rata pendapatan peternak Kecamatan Kalawat per tahun sebesar Rp. 1.570.013,2.

\section{Keuntungan Usaha Pemeliharaan Ternak Sapi}

Keuntungan merupakan selisih antara penerimaan yang diperoleh dengan total biaya yang dikeluarkan. (Rasyaf, 2000). Berdasarkan hasil penelitian diketahui bahwa total biaya produksi yang dikeluarkan peternak per tahun sebesar Rp. 231.801.283 dengan rata-rata $\mathrm{Rp} 7.726 .709,4$ per responden. Sedangkan total penerimaan usaha ternak sapi per tahun sebesar Rp. 412.880.250 dengan rata-rata $\mathrm{Rp} \quad 13.762 .675$ per responden. Keuntungan yang diperoleh dari beternak sapi sebesar Rp. 181.078.967 dengan rata-rata keuntungan responden sebesar Rp. 6.035.965,6.

\section{Pendapatan dari Usaha Tani dan Pendapatan Luar Usaha Tani}

Total pendapatan responden dalam usaha tani sebesar $\mathrm{Rp}$ 414.087.500 dengan rata-rata pendapatan petani sebesar Rp 13.802.916,67 per tahun. Pendapatan dari usaha di luar pertanian sebesar Rp 402.120.000 dengan rata-rata pendapatan sebesar Rp 13.404.000 per tahun. Pendapatan usaha ternak selain ternak sapi sebesar Rp 20.004.000 dengan rata-rata pendapatan sebesar Rp 666.800 per tahun.

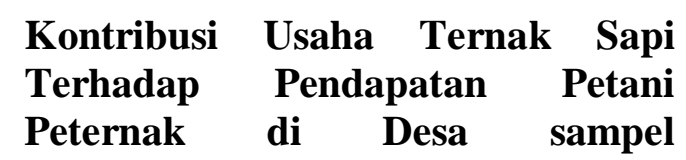




\section{Kecamatan Kalawat Kabupaten Minahasa Utara}

Untuk mengukur besarnya kontribusi usaha ternak sapi terhadap pendapatan petani, maka perlu diketahui besarnya pendapatan dari masing-masing usaha yang terdiri dari usaha pertanian dan usaha di luar pertanian. Besarnya pendapatan dari usaha tani adalah sebesar Rp. 615.008.467/tahun dengan rata-rata pendapatan sebesar Rp. 20.500.282/tahun. Pendapatan responden diluar usaha tani adalah sebesar Rp. 402.120.000/tahun dengan rata-rata pendaoatan per responden sebesar Rp. 13.404.000/tahun. Berdasarkan model analisis perhitungan yang ditentukan, maka untuk mengetahui besarnya kontribusi ternak sapi terhadap pendapatan petani adalah sebagai berikut :

$$
\mathrm{A}=
$$

181.916 .967

$181.916 .967+615.008 .467+402.120 .000$

X $100 \%$

$$
\begin{aligned}
= & \\
\frac{180.916 .967}{1.017 .128 .467} \times 100 \% & \\
= & 17,78 \%
\end{aligned}
$$

Hasil penelitian menunjukkan bahwa kontribusi usaha ternak sapi terhadap total pendapatan petani di Kecamatan Kalawat Minahasa Utara adalah sebesar 17,78

\section{KESIMPULAN}

\section{Kesimpulan}

Pendapatan dari usaha ternak sapi di Kecamatan Kalawat Kabupaten Minahasa Utara sebesar Rp.180.916.967/tahun dengan kontribusi terhadap pendapatan petani sebesar $17,78 \%$.

\section{Saran}

Perlu adanyapenyuluhan dari Instansi terkait akan pentingnya kontribusi ternak sapi terhadap tambahan pendapatan petani, serta adanya penelitian lebih lanjut tentang bagaimana pemanfaatan dari usaha ternak sapi di Kecamatan Kalawat Kabupaten Minahasa Utara

\section{DAFTAR PUSTAKA}

BP3K Kecamatan Kalawat. 2011. Data Statistik BP3K Kecamatan Kalawat, Kecamatan Kalawat Kabupaten Minahasa Utara Sulawesi Utara.

Cochran, W.G. 2005. Teknik Penarikan Sampel. Jakarta: Penerbit Universitas Indonesia.

Jogiyanto.2008. Metodologi Penelitian Sistem Informasi.C.V ANDI, Yogyakarta.

Mulyono, Sdan B.Sarwono. 2004. Beternak Domba Prolifik. Penebar Swadaya. Jakarta.

Mustafa,H.2000.TeknikPengambilan

Sampel.http://bioz08alwaysfighti ngforbetter future. [12 Desember 2012].

Rahim,Adan R.D.H. Diah. 2008. Pengantar, Teori, dan Kasus Ekonomika Pertanian. Cetakan Kedua. Jakarta: Penebar Swadaya.

Rasyaf. M. 2000. Memasarkan Hasil Peternakan. Swadaya. Jakarta.

Sihombing. 2000.

TeknikPengolahanLimbahKegiata n Usaha Peternakan. PenelitianLingkunganHidup. LembagaPenelitian, IPB Bogor. 
Susilorini, T.E; M.E. Sawitri; dan Murhalien. 2011. Budi Daya 22 Ternak Potensial. Penebar Swadaya. Jakarta.

Suyatna, I.Gdan M.Antara. 2004.

Bahan Ajar Metodologi Penelitian. Denpasar: Program S2
Magister Agribisnis Universitas Udayana.

Tarandung, N.S. 2004. Analisis Keuntungan Pemeliharaan Ternak Sapi Di Kecamatan Langowan Barat. Skripsi. Fakultas Peternakan.Unsrat. Manado 